\title{
The helminth fauna of Apathya cappadocica (Werner, 1902) (Anatolian Lizard) (Squamata: Lacertidae) from Turkey
}

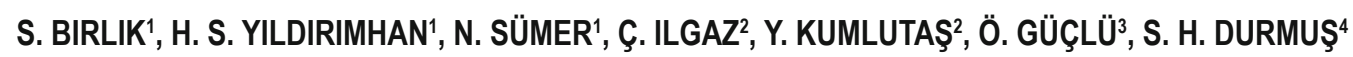

\begin{abstract}
1 Uludag University, Faculty of Arts and Sciences, Department of Biology, Nilüfer, Bursa, Turkey; ${ }^{2}$ Dokuz Eylül University, Faculty of Science, Department of Biology, 35160, Buca-Izmir, Turkey, E-mail: sezen@uludag.edu.tr, ${ }^{3}$ Aksaray University, Güzelyurt Vocational School, Department of Plant and Animal Production, 68500, Güzelyurt/Aksaray, Turkey; ${ }^{4}$ Dokuz Eylül University, Faculty of Education, Department of Biology, 35160, Buca-izmir, Turkey
\end{abstract}

\section{Article info}

Received May 28, 2015 Accepted June 4, 2015

\begin{abstract}
Summary
A total of thirty-one Anatolian Lizard, Apathya cappacocica, samples from several provinces of Eastern and South-Eastern Turkey were examined for helminths. Two species of Nematoda, including Spauligodon atlanticus, Skrjabinodon medinae; two species of Cestoda, including Mesocestoides sp. tetrahydia and Oochoristica tuberculata and one species of Acanthocephala, Centrorhynchus $\mathrm{sp}$. were found. This is the first helminth record of $A$. cappodocica from Turkey. A. cappadocica represents a new host record for each of the parasite species. $S$. atlanticus is reported from Turkey for the first time.
\end{abstract}

Keywords: Nematoda; Cestoda; Acanthocephala; Anatolian lizard; Apathya cappadocica; Turkey

\section{Introduction}

The Anatolian Lizard, Apathya cappadocica (Werner 1902) is found in Turkey (central, eastern, southern and southeastern Anatolia), northern Syria, northern Iraq, and northwestern Iran (Ilgaz et al., 2010; Baran et al., 2012). A. cappadocica is medium sized lizard with a total length up to $25 \mathrm{~cm}$. The vertical distribution of the species varies from 300 and $1.700 \mathrm{~m}$. asl. This species was found exclusively in rocky, stony or pebbly areas and outcrops with sparse vegetation and rock mounds. It is occasionally seen in wooded areas. It could move easily from sunlight to shadow and could take refuge in crevices. The females lay between three and seven eggs. It is not known from modified habitats (Baran \& Atatür, 1998; Clark \& Clark, 1973; Anderson, 1999).

To our knowledge, only 14 (20\%) of the 69 lizards reported to occur in Turkey (Uetz, 2012) have been examined for helminths: Danford's Lizard, Anatololacerta danfordi (Gürelli et al., 2007); Slow Worm, Anguis fragilis (Schad et al., 1960) Turkish Worm Lizard, Blanus strauchi (Yıldırımhan et al., 2009); Turkish Gecko, Hemidactylus turcicus (Tinar, 1982), Balkan Emerald Lizard, Lacerta trilineata (Yıldırımhan et al., 2011); European Green Lizard, Lacerta viridis (Schad et al., 1960); Caucasian Agama, Paralaudakia caucasia (Yıldırımhan et al.,2006); Roughtail Rock Agama, Stellagama stellio (Yıldırımhan et al., 2006); Dwarf Lizard, Par- vilacerta parva (Saygı \& Olgun, 1993); Crimean Wall Lizard, Podarcis tauricus (Schad et al., 1960); Pleske's Racerunner-Transcaucasian Racerunner, Eremias pleskei, Strauch's Racerunner, Eremias strauchi, Suphan Racerunner, Eremias suphani (Düsen et al., 2013); Ocellated Skink Chalcides ocellatus (Incedogan et al., 2014).

This is the first detailed helminthological study conducted on $A$. cappadocica from Turkey. The purpose of this paper is to provide an initial helminth list for $A$. cappadocica.

\section{Material and Methods}

In total a thirty-one lizard samples were collected in 2014 from 5 localities in Turkey. The locations of all of the study sites within 5 localities in Turkey are shown in Fig.1. Thirty-one specimens of A. cappadocica (12 males, 15 females, 4 subadult, mean snoutvent length $=68,57 \pm 11,46 \mathrm{~mm}$, with a range from 46.0 to 87.0 $\mathrm{mm}$ ) were collected by hand in 2014 from Karabıyıklı village, Pazarcık, Kahramanmaraş (4) (37¹8'N, 37¹1'E, 930 m elevation, on 29 April 2014, n=12), Sakçagözü, Nurdağı, Gaziantep (3) $\left(37^{\circ} 10^{\prime} \mathrm{N}, 36^{\circ} 56^{\prime} \mathrm{E}, 806\right.$ m elevation, on 29 April 2014, $\left.n=4\right)$, Ceylanlı, Kırıkhan, Hatay (1) $\left(36^{\circ} 33^{\prime} \mathrm{N}, 36^{\circ} 22^{\prime} \mathrm{E}, 278\right.$ m elevation, on 1 May 2014, $n=2$ ), between Kilis and Hassa 32. km, Kilis (2) $\left(36^{\circ} 50^{\prime} \mathrm{N}, 36^{\circ} 53^{\prime} \mathrm{E}, 540 \mathrm{~m}\right.$ elevation, on 2 May 2014, $\mathrm{n}=6$ ) and 


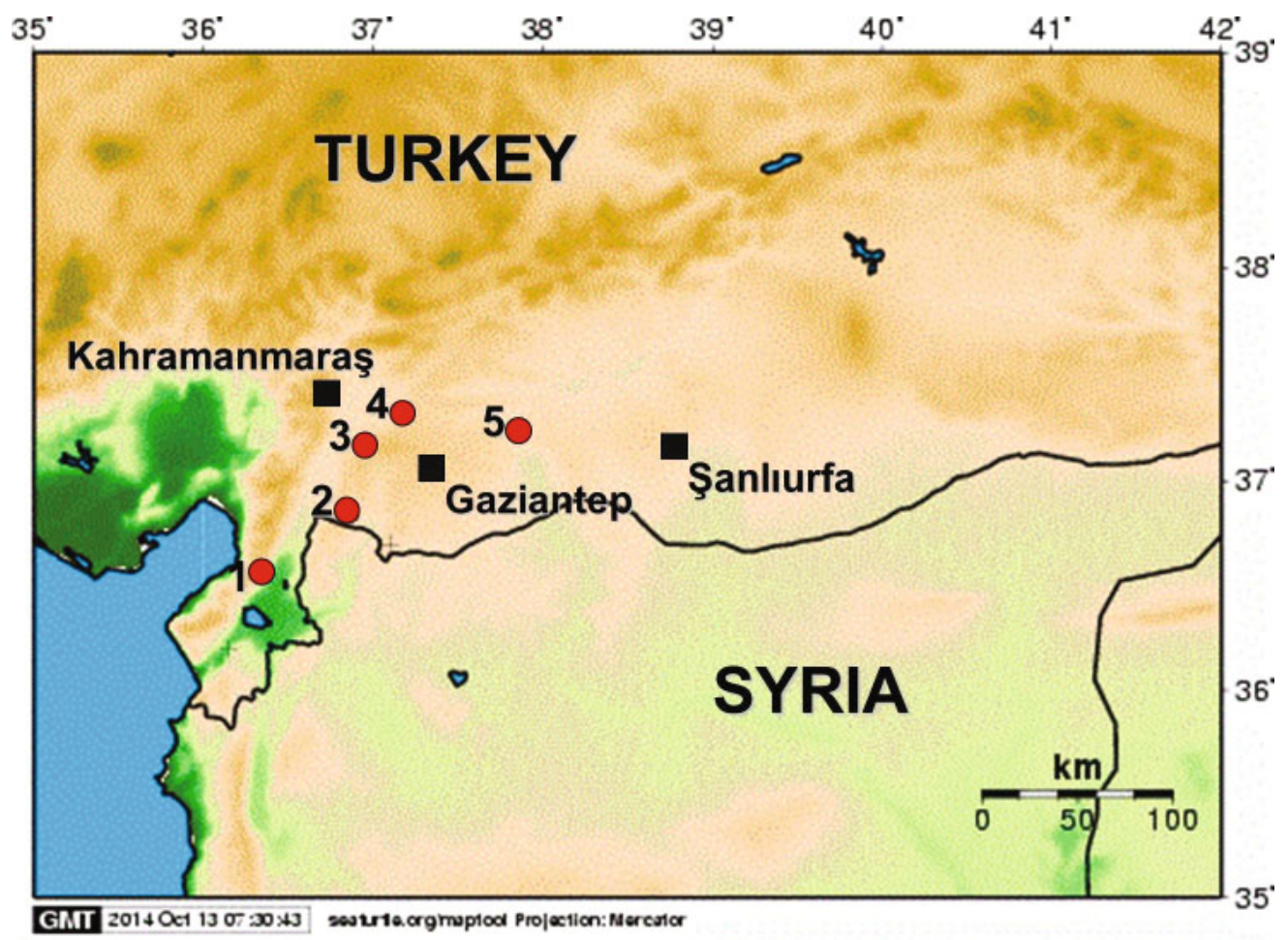

Fig.1. The collection locations of Apathya cappadocica from eastern and South-eastern part of Turkey

Halfeti, Şanlıurfa (5) $\left(37^{\circ} 14^{\prime} \mathrm{N}, 37^{\circ} 53^{\prime} \mathrm{E}, 590\right.$ m elevation, on 2 May $2014 n=7)$ Turkey. Lizards were transported to the laboratory, overanaesthetized with ether, sexed and body lengths measured. The body cavity was opened by a longitudinal incision and the gastrointestinal tract was removed by cutting across the oesophagus and rectum. The esophagus, stomach, small and large intestine, and lungs were opened and separately examined for helminths under a dissecting microscope. Nematodes were killed in hot saline solution, fixed in $70 \%$ ethanol, and mounted in glycerol. Cestodes were fixed in $70 \%$ ethanol, stained with iron-carmine as described by Georgiev et al. (1986), cleared in clove oil, and mounted in Entellan®. Helminth identification was based on keys given by Schmidt (1986), Petter and Quentin (1976), Yorke and Maplestone (1926), Yamaguti (1961, 1963), Baker (1987), Bray et al. (2008). Parasites were identified, when possible, to species, and the number and location of individuals of each species were recorded. The use of descriptive ecological terms follows Bush et al. (1997).

Helminth voucher specimens were deposited in the helminth collection of Uludag University Museum of Zoology, Bursa, Turkey. Lizard specimens were deposited in the Department of Biology, Dokuz Eylül University, İzmir, Turkey.

\section{Results}

Five species of helminth parasites were detected in Anatolian Lizard. These species were Mesocestoides sp., Oochoristica tuberculata (Cestoda); Spauligodon atlanticus, Skrjabinodon medinae (Nematoda); and Centrorhynchus sp. (Acanthocephala). Of $31 \mathrm{~A}$. cappadocica $21(67 \%)$ were infected with one or more parasites. Of 31 host lizard 10 (32\%) were infected by any parasite species. Total 235 individuals of 5 parasite species were collected from 21 Anatolian lizards.

Table1. Prevalence, mean intensity and mean abundance

\begin{tabular}{|c|c|c|c|c|}
\hline Helminth species & Site of infection & Prevalence (\%) & Mean intensity & Mean abundance \\
\hline \multicolumn{5}{|l|}{ Cestoda } \\
\hline Mesocestoides sp. (larvae) & body cavity & 9.67 & 14 & 1.35 \\
\hline Oochoristica tuberculata & small intestine & 3.22 & 1 & 0.03 \\
\hline \multicolumn{5}{|l|}{ Nematoda } \\
\hline Skrjabinodon medinae & caecum & 45.16 & 6.21 & 2.80 \\
\hline Spauligodon atlanticus & large intestine & 41.93 & 7.69 & 3.22 \\
\hline \multicolumn{5}{|l|}{ Acanthocephala } \\
\hline Centrorhynchus sp. & body cavity & 9.67 & 1.66 & 0.16 \\
\hline
\end{tabular}


Table 2. The lizard species studied in Turkey and identified helminth species.

(1. Schad et al. (1960) 2. Yıldırımhan et al. 2009 3. Tınar 1982. 4. Tınar 1983 5. Yıldırımhan et al. 2008 6. Saygı and Olgun 1993, 7. Yıldırımhan et al. 20118. Yıldırımhan et al. 2006 9.Gürelli et al. 2007 10. Düșen et al. 2013 11. Incedogan et al. 2014 12. ${ }^{*}$ Current study)

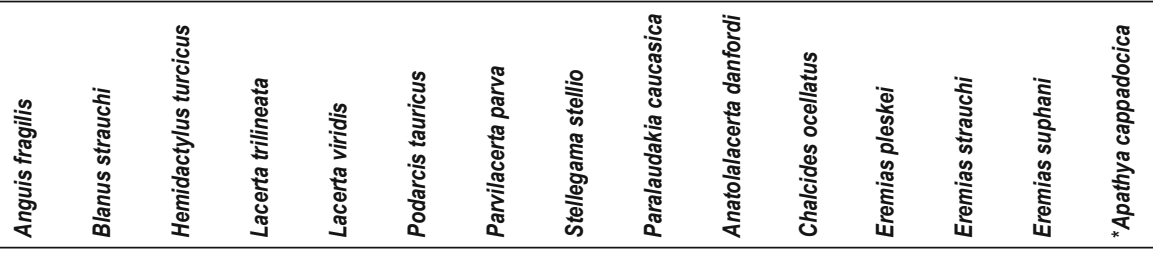

\section{Digenea}

Plagiorchis elegans

Pleurogenoides medians

Brachylaima sp. (metacercaria)

\section{Cestoda}

Oochoristica tuberculata

Joyeuxiella pasqualei

Mesocestoides sp. (tetrathyridia)

\section{Nematoda}

Abbreviata abbreviata

Ascarops strongylina (larva)

Ascaridae (larva)

Entomelas entomelas

Entomelas dujardini

Falcaustra armenica

Foleyella candezei

Moaciria icosiensis

Oswaldocruzia filiformis

Oswaldocruzia skrjabini

Oxysomatium brevicaudatum

Pharyngodon mamillatus

Pharyngodon inermicauda

Parapharyngodon bulbosus

Parapharyngodon kasauli

Parapharyngodon tyche

Parapharyngodon micipsae

Physaloptera sp. (larva)

Skrjabinodon medinae

Skrjabinodon aegyptiacus

Skrjabinelazia hoffmanni

Skrjabinelazia taurica

Spauligodon sp.

Spauligodon atlanticus

Spauligodon eremiasi

Spauligodon laevicauda

Spauligodon saxicolae

Spinicauda sonsinoi

Strongyluris calotis

Thelandros baylisi

Thelandros taylori

Thelastomoides sp.

Acanthocephala

Macracanthorhynchus catulinus Acanthocephal cystacanth stage Centrorhynchus sp.

$$
\begin{aligned}
& \begin{array}{llllllllllllll}
-- & -- & -- & 7 & -- & -- & -- & -- & -- & -- & -- & -- & - & -
\end{array} \\
& \begin{array}{llllllllllllll}
-- & -- & -- & 7 & -- & -- & -- & -- & -- & -- & -- & -- & -- & -
\end{array} \\
& \begin{array}{lllllllllllllll}
-- & --- & -- & 7 & -- & -- & -- & -- & 8 & -- & 11 & -- & -- & 10 & 12
\end{array}
\end{aligned}
$$

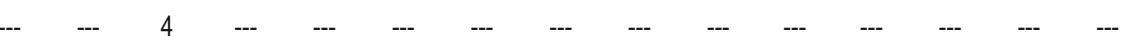

$$
\begin{aligned}
& \begin{array}{lllllllllllllll}
-- & -- & -- & 7 & -- & -- & -- & -- & -- & 9 & -- & -- & -- & - & 12
\end{array}
\end{aligned}
$$

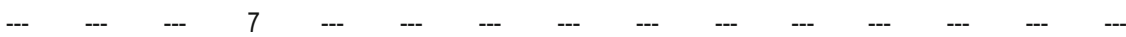

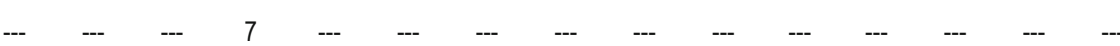$$
\begin{array}{llllllllllllll}
-- & -- & -- & -- & -- & -- & -- & 8 & -- & -- & -- & -- & -- & -
\end{array}
$$

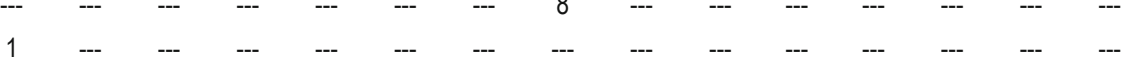$$
1 \text {--- }
$$

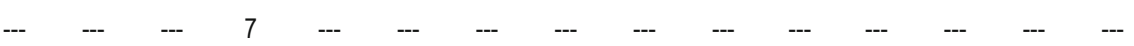

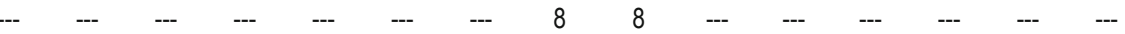

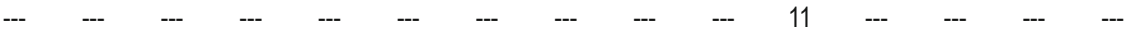

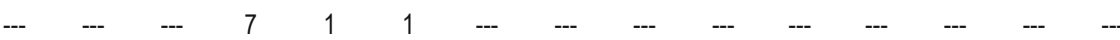$$
1 \text {--- }
$$$$
1 \text {--- }
$$

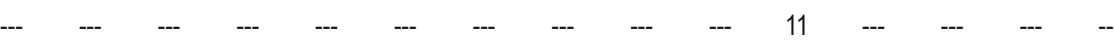

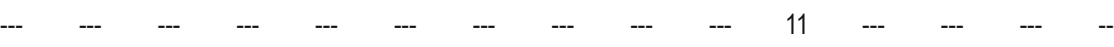

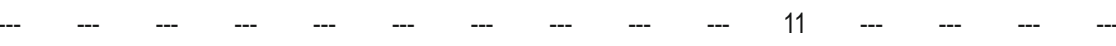

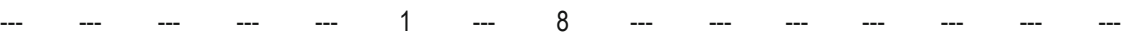

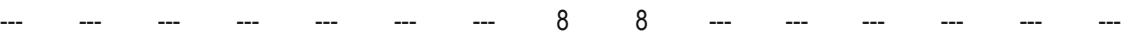

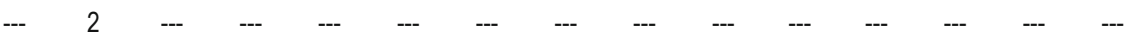

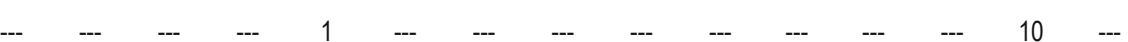

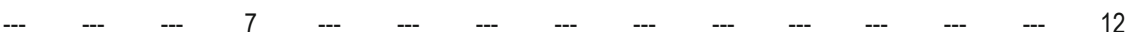

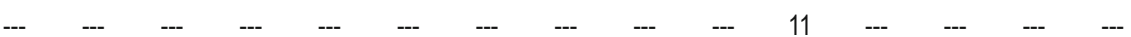

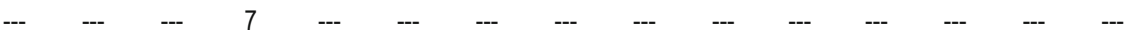

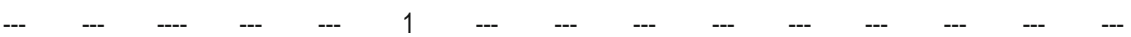

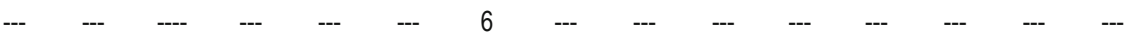

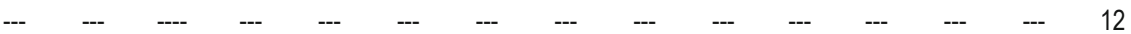

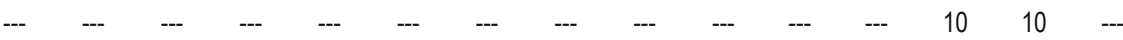

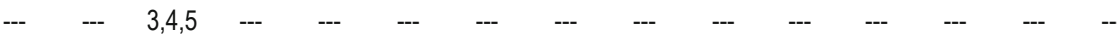

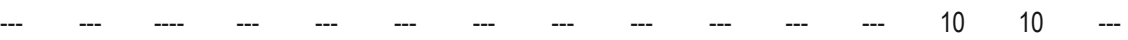

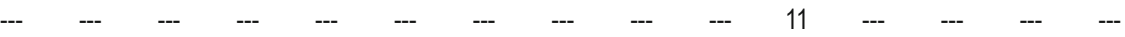

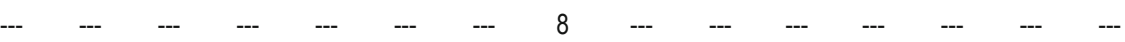

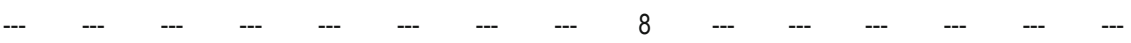

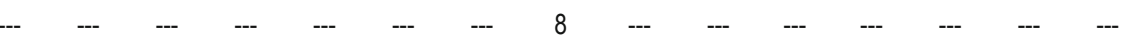

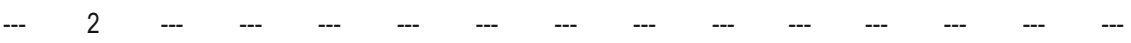$$
\begin{array}{lllllllllllllll}
-- & --- & 5 & -- & --- & --- & --- & -- & -- & -- & -- & -- & -- & -- & -- \\
--- & --- & --- & --- & --- & --- & --- & -- & -- & -- & -- & 10 & -- & -- & -- \\
--- & --- & --- & --- & --- & --- & --- & --- & --- & -- & -- & -- & -- & -- & 12
\end{array}
$$ 
The infection sites included the large intestine (rectum), small intestine, body cavitiy and caecum. S. atlanticus was the most prevalent species, followed by $S$. medinae. Infection prevalence, abundance and mean intensity of the parasites in A. cappadocica were given in Table 1.

\section{Discussion}

Total of 5 helminth species was found (2 Nematoda, 2 Cestoda, and 1 Acanthocephala). A total of 235 helminths were collected from $21(67 \%)$ of the 31 lizards examined, 5 helminth species were present in our survey; however, no host harboured more than 3 helminth species. The majority of infected lizards harboured only one helminth species; 11 lizard samples (52\%) harbored 1 species of helminth; 7 lizard samples (33\%) harbored 2 species; 3 lizard samples (14\%) harboured 3 species. There were $1.62 \pm$ $0.16(X \pm 1 \mathrm{SE})$ helminth species per infected lizard samples and $11.19 \pm 2.81$ helminth individuals per infected lizard samples.

A. cappadocica represents a new host record for each of the parasite species. S. atlanticus is reported from Turkey for the first time. All of these parasites species excluding $S$. atlanticus were previously reported from different lizards in Turkey (Table 2).

To our knowledge, there are no reports of helminths in A. cappadocica in the World.

In our study, male samples of $A$. cappadocica were more heavily infected by nematodes than female samples; the largest numbers of nematodes occurred in the caecum and large intestine.

Mesocestoides sp. was found in larval stages. This suggests that the A. cappadocica may be intermediate or paratenic hosts of this species. The ultimate host is presumably a predator of the lizards (possibly a bird or a mammal). The life cycle of Mesocestoides sp. is thought to require 3 hosts, i.e. a vertebrate definite host, a vertebrate second intermediate host, and a purported arthropod first intermediate host (Rausch, 1994). Tetrathyrida is frequently found in the body cavities of amphibians, reptiles, and rodents (Padgett \& Boyce, 2004). In our study, a total of 42 tetrathyrida were collected from 3 of 21 infected host lizard (14\%). A. cappadocica represents third host record for the genus Mesocestoides from Turkey. The first report of this genus was in the Lacerta trilienata from Bursa, Turkey (Yıldırımhan et al., 2011) and the second report was Anatolalacerta danfordi from western Turkey (Gürelli et al., 2007).

Some 85 species have been assigned to Oochoristica, a cosmopolitian genus of cestodes parasitic in reptiles, but because most species have not been recorded since their description, the number of species is questionable (Schuster, 2011). Bursey et al. (2010) list 17 species from the Palaearctic region. In our study, this species was observed only one host $(4,76 \%)$. This species was reported from Paralaudakia caucasica (Yıldırımhan et al. 2006), Lacerta trilineata (Yıldırımhan et al., 2011) and Chalcides ocellatus (Incedogan et al., 2014) from several localities in Turkey.

There are currently 47 nominal species of Spauligodon that occur in lizards assigned to the Agamidae, Chamaeleonidae, Gekkonidae, Lacertidae, Opluridae, Phrynosomatidae, Polychroticae, Scincidae, Teiidae and Tropiduridae. Of these 20 are found in the Palearctic realm. (Bursey \& Goldberg, 2011).

Species of Spauligodon are distinguished on the basis of the pres- ence or absence of a spicule the presence or absence of spines on the tail filament of adults, egg morphology and geographical distribution (Bursey et al., 2005). In our study, the pharyngodonid nematode found was S.atlanticus being the dominant helminth in all localities. This species was observed in 14 of 21 infected host lizard (66\%). A total of 87 parasite were collected from 14 host lizard. S. atlanticus from Turkey was reported for the first time. The pharyngodonid nematode found was Skrjabinodon medinae being the second dominant helminth in all localities. It was described by Garcia-Calvente (1948) as Pharyngodon medinae. This species was recorded in 13 of 21 host lizard (61\%). A total of 100 parasite collected from 11 host lizard. S. medinae was recorded from Lacerta trilineata, Bursa province from Turkey (Yıldırımhan et al., 2011). So this is the second report from Turkey for this helminth species. The acanthocephalans are distributed worldwide, and several reports on the presence of acanthocephalans had existed from lizards in Turkey (Yıldırımhan et al., 2008; Düsen et al., 2013). In this study, we reported as larvae of Centrorhynchus sp., However, the detailed species identification was not possible due to the absence of adult worms. Since the adults of this genus are known to be parasitic in birds, an experimental infection in birds is needed for species identification. Their intermediate hosts are terrestrial isopods or insects, Orthoptera or Coleoptera, and their various paratenic hosts, amphibians, reptiles, and mammals, play a fundamental role in their transmission to the birds (Buron \& Golvan, 1986). Amphibians and reptiles serve as paratenic hosts for some acanthocephalan species that mature in flesh-eating birds, and species of Centrorhynchus are known to be present in frogs, lizards and snakes. Centrorhynchus is the largest acanthocephalan genus having almost 90 species, and these are parasites mainly of birds of the orders Falconiformes and Strigiformes (Choi et al., 2010). In our study, this species was observed in 3 of 21 infected host lizard (14\%). A total of 5 parasites collected from 3 host lizard. There is only one species from Turkey for this genus. Centrorhynchus amphibius was recorded from Buteo buteo, Bursa province from Turkey (Tezel et al., In press).

Helminth species have been classified as core and secondary species according to their prevalence $(\mathrm{P})$ : species with prevalence $>30 \%$ redeemed core species and species with $10-30 \%$ prevalence is considered secondary species (Roca, 1993). In this survey S. atlanticus and S. medinae represent core species, Mesocestoides sp., Oochoristica tuberculata, Centrorhynchus sp. represent secondary species. Helminths infecting $A$. cappadocica are generalists and commonly found in European reptiles.

The low values of prevalence and mean intensities of infection (Tables 1 ) indicate that many members of the helminth infracommunities occurred only irregularly and occasionally. This agrees with the typical pattern of helminth infection in many reptiles, i.e. few species occur frequently, few species occur with moderate prevalence, and many species are rare (Aho 1990; Roca \& Hornero 1994).

Although several recent ecological studies are available on helminth communities of reptiles (Dobson et al., 1992), there is a paucity of data on the structure of the helminth communities of European reptiles (Roca \& Homero, 1994; Roca, 1995; Sanchis et al., 2000). Moreover, the structure of helminth communities in reptiles from the Palaearctic region has received little attention at 
both hierarchical levels of organization, the infracommunity and the component community. In Turkey, there is little knowledge available on the helminth fauna of lizards. At the present, studies of helminth fauna of lizards have been still scarce, incomplete and mainly from the point of view of taxonomy of parasites. Thus, additional studies will be required before the component community of helminths infecting Turkish lizards can be determined. A summary of known Turkish lizard helminths is presented in the Table 2.

\section{Acknowledgement}

The lizard samples used in this study were collected within the scope of the project supported by TUBITAK (The Scientific and Technological Research Council of Turkey), project number 112 T269.

\section{References}

ANDERSON, S.C. (1999): The Lizards of Iran, Society for the Study of Amphibians and Reptiles, Oxford, Ohio

Aно, J.M. (1990): Helminth communities of amphibians and reptiles: comparative approaches to understanding patterns and processes. In: Esch, G., Bush, A., Aно, J. (Eds) Parasite communities: patterns and processes. London, UK: Chapman and Hall, pp. 157 $-195$

Baker, M.R. (1987): Synopsis of the Nematoda Parasitic in Amphibians and Reptiles. Occasional Papers in Biology. Volume 11. St. John's Newfoundland, Canada: Memorial University of Newfoundland, $325 \mathrm{pp}$.

Baran, İ., Atatür, M.K. (1998): Herpetofauna of Turkey (Amphibia and Reptilia). Ankara (Çevre Bakanlığı), 214 pp. (In Turkish)

Bray, R., Gibson, D., Jones, A. (2008): Keys to the Trematoda. Vol. 3. London, CAB International, 824 pp.

Buron, I., Golvan, Y.J. (1986): Hosts of Acanthocephala I. Intermediate hosts [Les hôtes des Acanthocéphales: I. Les hôtes intermédiaires]. Ann. Parasitol. Hum. Comp., 61: 581 - 592

Bursey, C., Goldberg, S. (2011): A new species of Spauligodon (Nematoda: Oxyuroidea: Pharyngodonidae) in Laatastia longicauda (Sauria: Lacertidae) from Kenya. J. Parasitol., 97: 460 - 462. DOI: $10.1645 / G E-2645.1$

Bursey, C.R., Goldberg, S.R., Parmelee, J.R. (2005): Gastrointestinal helminths of 13 species of lizards from Reserva Cuzco Amazónico, Peru. Comp. Parasitol., 72: 50 - 68. DOI: $10.1654 / 4132$

Bush, A.O., Lafferty, K.D., Lotz, J.M., Shostak, A.W. (1997): Parasitology meets ecology on its own terms: Margolis et al. Revisited. J. Parasitol., 83(4): 575 - 583. DOI: 10.2307/3284227

Chol, C.J., Lee, H.J., Go J-H., Park, Y.K., Chal, J.Y., Seo, M. (2010): Extra intestinal migration of Centrorhynchus sp. (Acanthocephala: Centrorhynchidae) in Experimentally infected rats. Korean J. Parasitol., 48(2):139 - 143. DOI: 10.3347/kjp.2010.48.2.139

CLARK, R.J., CLARK, E.D. (1973): Report on a collection of amphibians and reptiles from Turkey. Occasional Papers of the California Academy of Science, San Francisco; 104: 62 pp.

Dobson, A.P., Pacala, S.W., Rougharden, J.D., Carper, E.R., HarRIS, E.A. (1992): The parasites of Anolis lizards in the northern
Lesser Antilles. I. Patterns of distribution and abundance. Oecologia, 91: 110 - 117

Dusen, S., Kumlutas, Y., Ilgaz,C., Yaka, H., Karadayı, F. (2013): Helminth Parasites of the Three Racerunner Lizards: Eremias pleskei Nikolsky, 1905 (Pleske's Racerunner-Transcaucasian Racerunner), Eremias strauchi Kessler, 1878 (Strauch's Racerunner) and Eremias suphani Basoglu \& Hellmich, 1968 (Suphan Racerunner) collected from Eastern Part of Turkey. Helminthologia, 50(2): 108 - 111, 2013. DOI 10.2478/s11687-013-0117-3

Garcia-Calvente, I. (1948): Revision del genero Pharyngodon y descripcion de especies neuvas. Rev. Iber. Parasitol., 8, 367 - 410 Georgiev, B.B., Biserkov, V.Y., Genov, T. (1986): In toto staining method for cestodes with iron acetocarmine. Helminthologia, 23: $279-281$

Gürelli, G., Göçmen, B., Çetin-DoĞan, T., Alpagut-Keskin, N. (2007): First record of Mesocestoides spp. Vaillant, 1863 Tetrathyridia (Cestoidea: Cyclophyllidae) in Anatolian lizard, Anatololacerta danfordi (Günther, 1876) in Turkey. North-Western J. Zool., 3(2): 96 - 104

Ilgaz, Ç., Arikan, H., Kumlutaş, Y., Avcl, A. (2010): Electrophoretic comparison of blood-serum proteins of Apathya cappadocica (Sauria, Lacertidae) subspecies from Anatolia. Acta Herpetol., 5(2): 207 - 215. DOI: 10.13128/Acta_Herpetol-9037

INCEDOgan, S., YILDIRIMHAN, H.S., BuRSEY, C.R. (2014): Helminth parasites of the ocellated skink, Chalcides ocellatus (Forskal,1775) (Scincidae) from Turkey. Comparative Parasitology. 81(2): 260 269. DOI: $10.1654 / 4708.1$

Padgett, K.A., Boyce, W.M. (2004): Life history studies on two molecular strains of Mesocestoides (Cestoda: Mesocestoididae): Identification of sylvatic hosts and infectivity of immature life stages. J. Parasitol., 90(1): 108 - 114. DOI: 10.1645/GE-100R1

Petter, A.J., Quentin, J.C. (1976): ClH keys to the nematode parasites of vertebrates. No. 4 keys to genera of the Oxyuroidea. 1st ed. Commonwealth Agricultural Bureaux International, Farnham Royal, U.K., 30 p.

RAUSCH, R.L. (1994): Family Mesocestoididae Fuhrmann, 1907. In: Khall, L.F, Jones, A., Bray, R.A. (Eds): Keys to the Cestode Parasites of Vertebrates. International Institute of Parasitology, Institute of $\mathrm{CAB}$ International, University Press, Cambridge, pp. 309 - 314 RocA, V. (1993): Helmintofauna dels reptils. In: Alcover, J.A., BALLEsteros, E., Fornós, J.J. (Eds). Historia natural de l'arxipelag de Cabrera. CSIC-Edit. Moll, Ciutat de Mallorca, 273 - 292

Roca V., Hornero M.J. (1994): Helminth infracommunities of Podarcis pityusensis and Podarcis lilfordi (Sauria: Lacertidae) from the Balearic Islands (western Mediterranean Basin). Can. J. Zool., 72: 658 - 664. DOI: 10.1139/z94-089

RocA, V. (1995): An approach to the knowledge of the helminth infracommunities of Mediterranean insular lizards (Podarcis spp.). In: Llorente, G.A., Montori, A. Santos, X., Carretero, M.A. (Eds), Scienta Herpetologica. AHE, Barcelona, pp.285 - 292

Sanchis, V., Rolg, J.M., Carretero, M.A., Roca, V., Llorente, G. (2000): Host-parasite relationships of Zootoca vivipara (Sauria: Lacertidae) in the Pyrenees (North Spain). Folia Parasitol. 47(2): 118 - 122. DOI: $10.14411 / \mathrm{fp} .2000 .024$

SAYGI, G., OLGUN, K. (1993): The nematode found in Dwarf Lizard (Lacerta parva) in Sivas province: Spauligodon.. Turk. Parazitol. Derg., 17(1): 40 - 45 (In Turkish) 
Schad, G.A., Kuntz, R.E., Wells, W.H. (1960): Nematode parasites from Turkish vertebrates. An annotated list. Can. J. Zool., 38: 949 - 963. DOI: 10.1139/z60-101

SCHUSTER, R.K. (2011): Oochoristica chalcidesi n. sp. (Eucestoda: Linstowiidae) from the ocelated skink, Chalcides ocellatus (Forsskal, 1775) in the United Arab Emirates. J. Helminthol, 85(4): 468 - 471. DOI: $10.1017 /$ S0022149X10000842

ScHmidT, G. D. (1986): Handbook of Tapeworm Identification. CRC Press, Boca Raton, Florida. 675 pp.

Tezel, M., GirişGin A.O., Birlik, S., Yildirimhan, H.S., Şenlik, B.: Helminths of the digestive tract in Buteo buteo (Falconiformes: Falconidae) in Bursa province of Northwest Turkey. Turk. J Zool., DOI:10.3906/ZOO-1403-24 (In press)

TINAR, R. (1982): The finding of Pharyngodon laevicauda Seuret, 1914 from Hemidactylus turcicus lizards in Southern Anatolia. A.Ü. Vet. Fak. Derg., 29 (1 - 2): 164 - 174 (In Turkish)

TINAR, R. (1983): The helminthologic research in Hemidactylus turcicus lizards from Southern Anatolia. U. Ü. Vet. Fak. Dergisi., 2 (1): 1 - 7 (In Turkish)

YAMAGUTI, S. (1961): Systema Helminthum: The Nematodes of Ver- tebrates. Vol. III, Part II. Nematodes of Amphibians. Intersciences Publishers, London, England. 679 pp.

Yamaguti, S. (1963): Systema Helminthum. Acanthocephala. Vol. V. Intersciences Publishers, London, England. 423 pp.

YildirimHan, H.S., GoldBerg, S.R., BuRSEY, C.R. (2006): Helminth parasites of the Caucasian agama, Laudakia caucasia, and the roughtail rock agama, Laudakia stellio (Squamata: Agamidae) from Turkey. Comp. Parasitol., 73: 257 - 262, DOI: 10.1654/4205.1 YILDIRIMHAN, H.S., SüMeR, N., YILMAZ, N. (2008): The helminth fauna of Hemidactylus turcicus (Mediterrenaen Gecko) (Linnaeus, 1758) from Hatay province. Acta Parasitol. Turcica., 32: 393 - 395 (In Turkish) YILdIRIMHAN, H.S., YILMAZ, N., İncEdoĞAN, S. (2009): Helminth Fauna of the Anatolian Worm Lizard, Blanus strauchi (Bedriaga, 1884) from Hatay. Türk. Parazitol Derg., 33(4): 327 - 329

Yildirimhan, H.S., Bursey, C.R., Altunel, F.N. (2011): Helminth parasites of the Balkan green lizard Lacerta trilineata Bedriaga 1886 from Bursa, Turkey. Turk. J. Zool., 35(4): 519 - 535. DOI: 10.3906/ ZOO-0910-1

Yorke, W., Maplestone, P.A. (1926): The nematode parasites of vertebrates. London, UK, J. and A. Churchill. 536 pp. 